\title{
ERRATUM
}

The Journal of Microbiology, April 2009, p. 178-186

DOI 10.1007/s12275-008-0307-8

Vol. 47, No. 2

Copyright (c) 2009, The Microbiological Society of Korea

\section{Erratum to: Intracellular Substrates of a Heme-Containing Ascorbate Oxidase in Pleurotus ostreatus}

\author{
Seung-Rock Lee ${ }^{1 *}$, Woo-Jeong $\mathrm{Joo}^{2}$, Yong-Un Baek ${ }^{2}$, Youn-Kyong Lee ${ }^{2}$, Seong-Woon $\mathrm{Yu}^{2}$, Yeon-Ran Kim ${ }^{2}$, \\ Kee-Oh Chay ${ }^{1}$, Seung-Hyun $\mathrm{Cho}^{2}$, and Sa-Ouk Kang ${ }^{2 *}$ \\ ${ }^{1}$ Department of Biochemistry, Chonnam National University Medical School, Gwangiu 501-190, Republic of Korea \\ ${ }^{2}$ Laboratory of Biophysics, School of Biological Sciences and Institute of Microbiology, Seoul National University, Seoul 151-742, \\ Republic of Korea \\ (Received December 19, 2008 / Accepted February 12, 2009)
}

In the online version of the article the name of the second corresponding author is misspelled. The correct spelling is Sa-Ouk Kang.

The online version of the original article can be found under doi: $10.1007 / \mathrm{s} 12275-008-0307-8$ 